\title{
Flash vacuum pyrolysis of azolyl-malonamates. Synthesis of 5-hydroxy-azolopyrimidin-7-ones
}

\author{
Walter J. Peláez, Ioulia T. Gafarova, and Gloria I. Yranzo* \\ Instituto de Investigaciones en Físico-Química de Córdoba (INFIQC) - Dpto. de Química \\ Orgánica - Facultad de Ciencias Químicas - Universidad Nacional de Córdoba - Ciudad \\ Universitaria - 5000 - Córdoba - Argentina \\ E-mail: yranzogi@dqo.fcq.unc.edu.ar
}

\section{Dedicated to Prof. Roberto A. Rossi on his $60^{\text {th }}$ Anniversary and to Prof. Edmundo A. Rúveda on his $70^{\text {th }}$ Anniversary \\ (received 09 Jul 03; accepted 09 Sep 03; published on the web 24 Sep 03)}

\begin{abstract}
The synthesis and flash vacuum pyrolysis (fvp) reactions of ethyl 3-oxo-3-(1,3-thiazol-2ylamino)propanoate (1) and of ethyl 3-oxo-3-(4H-1,2,4-triazol-3-ylamino)propanoate (2) are described in this article.

The synthesis of both compounds was performed by reaction of the corresponding aminoheterocycle and diethylmalonate with higher yields than previously described methodologies.

Flash vacuum pyrolysis reactions of 1 were performed between 300 and $500^{\circ} \mathrm{C}$. Reactions between 300 and $430^{\circ} \mathrm{C}$ afforded ethanol and 5-hydroxy-7H-[1,3]thiazolo[3,2-a]pyrimidin-7-one (3) and between 450 and $500^{\circ} \mathrm{C}$ carbon suboxide (4), 2-aminothiazole (5) along with 3 and ethanol were formed. Compounds $\mathbf{4}$ and $\mathbf{5}$ were formed a higher temperatures from $\mathbf{3}$, as was demonstrated by an independent reaction of $\mathbf{3}$. Reactions of $\mathbf{1}$ over solid catalysts (zeolites and hydrotalcites) were also carried out. In both cases they afforded about $40 \%$ of 3 at $250^{\circ} \mathrm{C}$.

Flash vacuum pyrolysis reactions of 2 were carried out between 300 and $450^{\circ} \mathrm{C}$. Up to $430^{\circ} \mathrm{C}$ the isolated products were ethyl-3-(3-amino-1H-1,2,4-triazol-1-yl)-3-oxopropanoate (6), 5hydroxy[1,2,4]triazolo[1,5-a]pyrimidin-7(4H)-one (7) and ethanol. From 430 to $450^{\circ} \mathrm{C}$ decomposition of $\mathbf{2}$ by a different mechanism than reactions at lower temperatures afforded 1,2,4-triazole (8), ethoxyoxazirene (9) and probably ketene (10) (not detected).

Reaction paths explaining reactions of $\mathbf{1}$ and $\mathbf{2}$ are discussed.
\end{abstract}

Keywords: Flash vacuum pyrolysis, 5-hydroxy-pyrymidin-7-ones, thiazoles, triazoles, catalysis 


\section{Introduction}

For several years our group has studied the flash vacuum pyrolysis of nitrogen heterocycles in homogeneous and heterogeneous systems. ${ }^{1}$ Most of these studies were performed on relatively simple heterocycles in order to obtain ring reactions and to determine the influence of substituents on their reactivity. To complete these studies, more complex molecules were selected in order to establish the most reactive zone in the molecule in cases where there are several. Thus, ethyl 3-oxo-3-(1,3-thiazol-2-ylamino)propanoate (1) and ethyl 3-oxo-3-(4H1,2,4-triazol-3-ylamino)propanoate (2) (Figure 1) were selected for our studies.

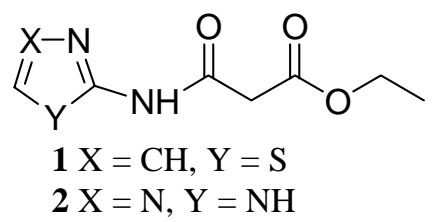

Figure 1

As it can be seen in Figure 1, these molecules have different reactive sites, a heterocyclic ring, an amide group, and an ester group. Concerning the heterocyclic ring, the 1,2,4-triazole ring in 2 may afford nitrogen extrusion from the tautomer with $\mathrm{N}=\mathrm{N}$ double bond (through a [1,5] $\mathrm{H}$ shift), as in pyrazoles ${ }^{1}$ or 1-phenyl-1,2,4-triazole reactions. ${ }^{2}$ The thiazole ring is very stable and in case of reaction in this site, a ring fragmentation $([5 \rightarrow 3+2])$ might be expected. Looking at the amide group, it was reported that reaction of $\mathrm{N}$-(1,5-dimethyl-2-pyrryl)-methylbenzamide afforded 1-methyl-2,5,dimethylene-2,5-dihydro-pyrrole. This reaction was explained by a threestep sequence involving two [3,3] shifts followed by a $\beta$ elimination of benzimidic acid. ${ }^{3}$ Concerning the ester part of the molecules, it was described that thermal reactions of $\beta$ ketoesters afford elimination of $\mathrm{CO}_{2}$ and formation of ketones. ${ }^{4}$ Besides, alkene elimination from esters with a $\beta \mathrm{H}$ is a very well known reaction, which is also possible in the selected compounds. ${ }^{5}$ There is also a very interesting reaction, which is an acyl migration to give an amide, in reactions of 1- and 2-(chloroacetyl)-3-aminopyrazoles. These compounds rearrange over a period of a few days at room temperature in the solid state to 3-(chloroacetamido)pyrazole. ${ }^{6}$ The inverse of this reaction, which is acyl migration from the amide, is another possibility in compounds presented in this paper. Sometimes pyrolytic reactions are compared with reactions that take place in a mass spectrometer, there is a report on mass spectra of ring substituted analogs of $\mathbf{1}$ where ethylene elimination and $\mathrm{CO}_{2}$ are reported as the first reactions after electron impact, suggesting that this may be the weakest part of the molecule. ${ }^{7}$ It must also be considered that different reactions may also take place simultaneously in compounds described in Figure 1, if they have more or less the same energy. If this is the case, these reactions would not have any synthetic. 


\section{Results and Discussion}

The starting materials, $\mathbf{1}$ and $\mathbf{2}$ were prepared by a modification of a previously reported reaction of diethylmalonate and the corresponding aminoheterocycle. ${ }^{7}$ The yields of $\mathbf{1}$ and $\mathbf{2}$ were increased by changing temperature and reaction times.

\section{Flash vacuum pyrolysis of ethyl 3-oxo-3-(1,3-thiazol-2-ylamino)propanoate (1)}

Reactions were carried out between 250 and $500{ }^{\circ} \mathrm{C}$, with contact times of $\sim 10^{-2} \mathrm{~s}$ and are depicted in Table 1. The mass balance in all reactions was $>90 \%$ and in each run about $40 \mathrm{mg}$ of 1 was pyrolyzed. Between 300 and $430 \quad{ }^{\circ} \mathrm{C}, \quad \mathbf{1}$ afforded 5-hydroxy-7H-[1,3]thiazolo[3,2-a]pyrimidin-7-one (3) and ethanol while at higher temperatures carbon suboxide (4), 2-aminothiazole (5) were also formed as shown in Scheme 1.

Table 1. Flash vacuum pyrolysis of $\mathbf{1}$

\begin{tabular}{ccccc}
\hline $\mathrm{T}^{\circ} \mathrm{C}$ & $\% 1^{\mathrm{a}}$ & $\% 3^{\mathrm{a}}$ & $\% 5^{\mathrm{a}}$ & Others \\
\hline 250 & 100 & --- & -- & --- \\
300 & 84.0 & 16.0 & -- & $\mathrm{CH}_{3} \mathrm{CH}_{2} \mathrm{OH}$ \\
400 & 66.4 & 33.6 & -- & $\mathrm{CH}_{3} \mathrm{CH}_{2} \mathrm{OH}$ \\
430 & 49.2 & 50.8 & Traces & $\mathrm{CH}_{3} \mathrm{CH}_{2} \mathrm{OH}$ \\
450 & 11.7 & 79.9 & 8.4 & $\mathrm{CH}_{3} \mathrm{CH}_{2} \mathrm{OH}+4^{\mathrm{c}}$ \\
500 & 12.7 & 48.7 & 38.6 & $\mathrm{CH}_{3} \mathrm{CH}_{2} \mathrm{OH}+4^{\mathrm{c}}$ \\
\hline
\end{tabular}

${ }^{\mathrm{a}}$ Relative yields by ${ }^{1} \mathrm{H}-\mathrm{NMR}$ (DMSO- $d_{6}$ ). ${ }^{\mathrm{b}}$ Not quantified. ${ }^{\mathrm{C}}$ Identified by GC/MS .

The ${ }^{1} \mathrm{H}$-NMR $\left(\delta=5.30 \mathrm{ppm}\right.$, enolic H; lit. $\left.5.28 \mathrm{ppm}^{8}\right)$ and ${ }^{13} \mathrm{C}$-NMR spectra of 3 suggest that the enolic tautomer is the only one present, in accordance with previously reported results. ${ }^{8}$

The intermediate $\mathbf{1 1}$ is proposed on the basis of previously reported reactions of aminothiazoles ${ }^{9}$ and bis-(2-aminobenzothiazoly-6-yl)sulphone with $\mathrm{BrCH}_{2} \mathrm{COPh}^{10}$ where similar compounds with an exocyclic NH double bond and a heterocyclic N-acyl bond are formed. Formation of $\mathbf{1 1}$ is also the inverse reaction of 1- and 2-(chloroacetyl)-3-aminopyrazoles which rearrange over a period of a few days at room temperature in the solid state to 3(chloroacetamido)pyrazole as was stated above. ${ }^{6}$

Compounds $\mathbf{4}$ and $\mathbf{5}$ that are formed a higher temperatures may appear from two reactions, decomposition of $\mathbf{3}$ or from $\mathbf{1}$ by a different reaction. To check which of theses hypothesis was right, reactions of 3 at $500{ }^{\circ} \mathrm{C}$ were performed. These reactions were analyzed by GC/MS and ${ }^{1} \mathrm{H}-\mathrm{NMR}$ and reaction products were $\mathbf{4}$ (identified by its MS spectrum) and $\mathbf{5}$ (identified by its MS and ${ }^{1} \mathrm{H}-\mathrm{NMR}$ spectra by comparison with authentic sample). The yield of $\mathbf{5}$, relative to $\mathbf{3}$, was $40 \%$. It is interesting to note that this is the inverse reaction of the synthesis of $\mathbf{3}$ described by Ziegler et al. ${ }^{11}$ 


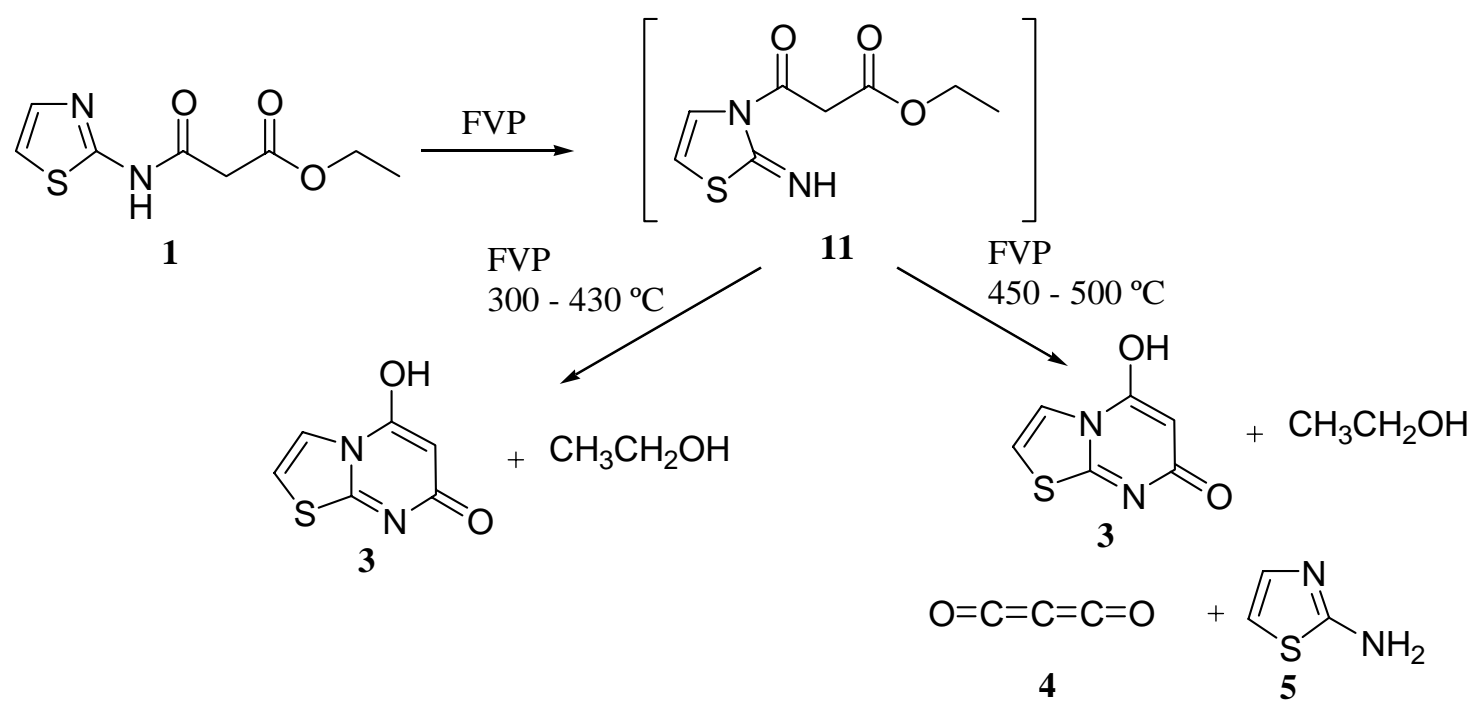

\section{Scheme 1}

Reactions of 1 at $430{ }^{\circ} \mathrm{C}$ with toluene as carrier gas were carried out to detect the presence of radicals. No bibenzyl was found in the products while monitored by GC/MS, so a radical chain reaction can be ruled out, supporting the mechanism depicted in Scheme 1.

\section{Flash vacuum pyrolysis of ethyl 3-oxo-3-(1,3-thiazol-2-ylamino)propanoate (1) over solid catalysts}

These reactions were carried out to check the influence of zeolites and hydrotalcites in fvp of $\mathbf{1}$. In previous research we have studied the effect of zeolites and hydrotalcites on fvp of pyrazoles. $^{12,13}$ Particularly in the case of zeolites, pyrazoles have different reaction products in comparison with fvp in homogeneous system. Ring fragmentations and isomerizations were found as well as nitrogen extrusion at lower temperatures. In those cases the difference in reactivity was adjudicated to the effect of ring substitution as the shape and the volume of the molecule are critical inside zeolite's cavity. The presence of Brönsted sites in the catalyst was also very important because different results were obtained with Na zeolite. ${ }^{12}$

Reactions of 1 over zeolite HY-22 were carried out between 200 and $250{ }^{\circ} \mathrm{C}$. In a typical run, $250 \mathrm{mg}$ of zeolite were included into the reactor mixed with glass wool and about $40 \mathrm{mg}$ of $\mathbf{1}$ were pyrolyzed. The results are shown in Table 2, where it is clear that zeolite lowers the reaction temperature (compared with the homogeneous system) to afford a good yield of 3 . However, the mass balance was lower than $70 \%$ due perhaps to the fact that starting material and/or products are adsorbed in the catalyst.

Reactions of 1 over hydrotalcite with $\mathrm{CO}_{3}{ }^{2}$ as interlaminar anion were carried out at $250{ }^{\circ} \mathrm{C}$. In a typical run, $1,2 \mathrm{~g}$ of the catalyst was mixed with glass wool and introduced inside the reactor and about $50 \mathrm{mg}$ of $\mathbf{1}$ were pyrolyzed. The only products detected in the ${ }^{1} \mathrm{H}$-NMR spectrum were 3, 5 and ethanol (Table 2). In these reactions the mass balance was rather poor $(<70 \%)$ also 
attributed to adsorption of starting materials and/or products on the catalyst. Compound $\mathbf{4}$ was detected and identified by GC/MS.

Table 2. Flash vacuum pyrolysis of 1 over solid catalysts

\begin{tabular}{cccccc}
\hline $\mathrm{T}^{\mathrm{o}} \mathrm{C}$ & Catalyst & $\% 1^{\mathrm{a}}$ & $\% 3^{\mathrm{a}}$ & $\% 5^{\mathrm{a}}$ & Others $^{\mathrm{b}}$ \\
\hline 200 & Zeolite $\mathrm{HY}-22(250 \mathrm{mg})$ & 100 & --- & --- & --- \\
250 & Zeolite $\mathrm{HY} 22(250 \mathrm{mg})$ & 17.7 & 64.7 & 17.7 & $\mathrm{CH}_{3} \mathrm{CH}_{2} \mathrm{OH}+4^{\mathrm{c}}$ \\
250 & $\begin{array}{c}\text { Hydrotalcite } \mathrm{Mg} / \mathrm{Al} / \mathrm{CO}_{3}{ }^{2} \\
(1,2 \mathrm{~g})\end{array}$ & 53.5 & 23.5 & 23.0 & $\mathrm{CH}_{3} \mathrm{CH}_{2} \mathrm{OH}+4^{\mathrm{c}}$ \\
\hline
\end{tabular}

${ }^{\text {a }}$ Relative yields by ${ }^{1} \mathrm{H}-\mathrm{NMR}$ (DMSO- $\left.d_{6}\right) .{ }^{\mathrm{b}}$ Not quantified. ${ }^{\mathrm{c}}$ Identified by GC/MS.

Comparing these results with those previously described for pyrazoles, there is one important difference. In reactions here described, there is no change in product composition when zeolite or hydrotalcite were used, only the reaction temperature is lowered. This fact was interpreted as a surface catalysis, independent of acid or basic sites. Pyrazoles reactions, on the contrary, are strongly directed by the presence of acid or basic sites. ${ }^{12,13}$ Besides, it is important to mention that decomposition of $\mathbf{3}$ is also improved as shown by the yield of $\mathbf{5}$ when compared with the homogeneous system.

It is worth noting that even if the reactions described here (catalyzed and non-catalyzed) don't have an excellent yield, they are a good alternative for synthesis of $\mathbf{3}$ or related compounds. Compound $\mathbf{3}$ was prepared by reaction of $\mathbf{4}$ and $\mathbf{5}$, in a difficult synthesis due to the generation of 4 in situ. ${ }^{11}$

Flash vacuum pyrolysis of ethyl 3-0xo-3-(4H-1,2,4-triazol-3-ylamino)propanoate (2)

The reactions of 2 were carried out between 300 and $450{ }^{\circ} \mathrm{C}$ and are described in Table 3 and Scheme 2.

Table 3. Flash vacuum pyrolysis of 2

\begin{tabular}{ccccc}
\hline $\mathrm{T}^{\circ} \mathrm{C}$ & $\% 2^{\mathrm{a}}$ & $\% 6^{\mathrm{a}}$ & $\% 7^{\mathrm{a}}$ & Others $^{\mathrm{b}}$ \\
\hline 300 & 66.7 & 13.3 & 20.0 & $\mathrm{CH}_{3} \mathrm{CH}_{2} \mathrm{OH}$ \\
400 & 24.4 & 28.9 & 46.7 & $\mathrm{CH}_{3} \mathrm{CH}_{2} \mathrm{OH}$ \\
410 & 12.7 & 36.4 & 50.9 & $\mathrm{CH}_{3} \mathrm{CH}_{2} \mathrm{OH}$ \\
430 & 6.5 & 41.3 & 52.2 & $\mathrm{CH}_{3} \mathrm{CH}_{2} \mathrm{OH}, 8,9,[10]$ \\
450 & --- & 52.6 & 47.4 & $\mathrm{CH}_{3} \mathrm{CH}_{2} \mathrm{OH}, 8,9,[10]$ \\
\hline
\end{tabular}

${ }^{\mathrm{a}}$ Relative yields by ${ }^{1} \mathrm{H}-\mathrm{NMR}$ (DMSO- $\left.d_{6}\right)$. ${ }^{\mathrm{b}}$ Not quantified.

These reactions can be explained by competing reactions as described in Scheme 2 . The first step is formation of compounds $\mathbf{1 2}$ and $\mathbf{1 3}$ analogous to $\mathbf{1 1}$ (Scheme 1). Acyl migration in $\mathbf{1 3}$ to 
afford $\mathbf{6}$ is a known reaction in azoles, as described in reactions of aminopyrazoles with acylating agents, ${ }^{14}$ and in reactions of N-substituted triazoles. ${ }^{15}$ The ${ }^{1} \mathrm{H}$ - NMR signal of H5 in 6 agrees with reported results of 1-substituted 1,2,4-triazoles where this proton is a lower fields. ${ }^{16}$ The structure of $\mathbf{6}$ is a 1-substituted 1,2,4-triazole and not 13, is supported by experimental evidence, as a cyclization reaction is expected in $\mathbf{1 3}$ and similar structures. Formation of $\mathbf{6}$ may be an indirect evidence of formation of 11, 12 and $\mathbf{1 3}$ in reactions of $\mathbf{1}$ and $\mathbf{2}$. In reactions at higher temperatures, 1,2,4-triazole $\mathbf{8}$ as well as a volatile compound identified as ethoxyoxazirene (9) by ${ }^{1} \mathrm{H}-\mathrm{NMR}$ and GC/MS, were formed.

Compounds 8 and 9 may be formed from a four membered ring intermediate (14) obtained by a nucleophilic attack of the NH of the amide to one of the carbonyls. Fragmentation of $\mathbf{1 4}$ should lead to the final products of this route. This mechanism suggests formation ketene (10) but it was not detected, due probably to its instability under reaction conditions.

As 8 was not found in all reactions at these temperatures, reactions of 2-amino-1,2,4-triazole were checked to see if triazoles are stable under these reaction conditions. The results showed gaseous products at $450{ }^{\circ} \mathrm{C}$ suggesting that triazole may also be unstable and may decompose at this temperature. As it was mentioned above, the structure of $\mathbf{9}$ was proposed on the basis of ${ }^{1} \mathrm{H}$ NMR and GC/MS of the crude reaction mixture, it could not be isolated because it readily decomposes at room temperature. Unfortunately, $\mathbf{1 0}$ was not detected, but is expected if a Retro Diels Alder reaction of the four membered ring in $\mathbf{1 4}$ is occurring.

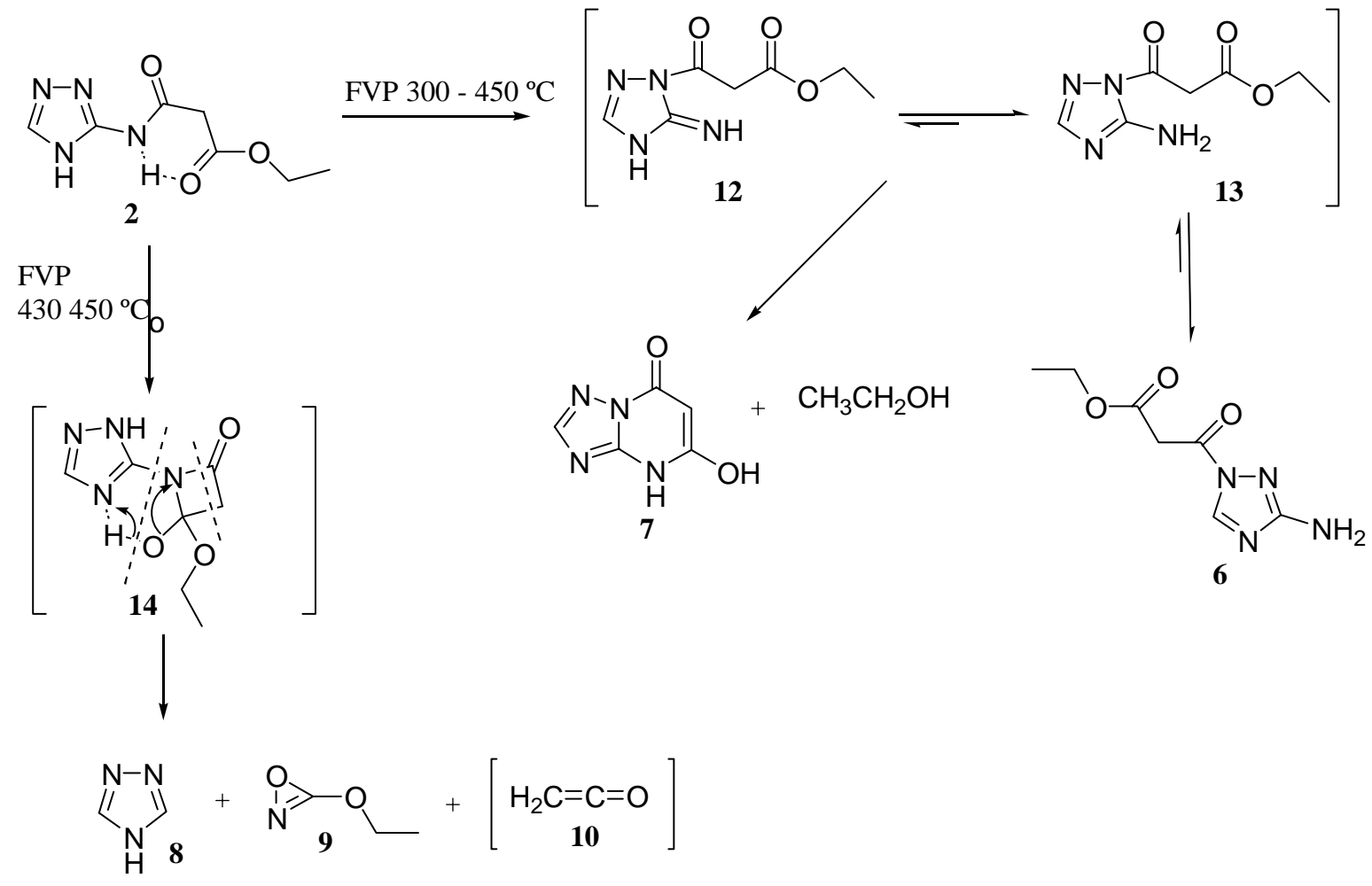

\section{Scheme 2}


Compound $\mathbf{7}$ is formed from $\mathbf{1 2}$ or $\mathbf{1 3}$ by a nucleophilic reaction, as described for $\mathbf{3}$ (Scheme 1). Although 3 and 7 have similar structures, with different heterocycles, 7 is a mixture of five possible tautomers, while $\mathbf{3}$ is not. This fact is clear in the ${ }^{13} \mathrm{C}-\mathrm{NMR}$ spectra of $\mathbf{7}$ where the signals of two $\mathrm{CH}_{2}$ (52.3 and $52.0 \mathrm{ppm}$ ) and three $\mathrm{CH}$ (79.6, 78.9 and $78.3 \mathrm{ppm}$ ) are present. Five tautomeric structures may be drawn (Scheme 3). According to the ${ }^{1} \mathrm{H}-\mathrm{NMR}$ spectrum, structures $\mathbf{c}$, $\mathbf{d}$ and $\mathbf{e}$ are predominant (broad signal at $4.92 \mathrm{ppm}$, integrating for $0.8 \mathrm{H}$ ). These results agree with the previously reported ones on the different tautomeric forms of 7 , suggesting that the enolic forms are predominant. Theoretical calculations also confirm this hypothesis. ${ }^{17-19}$ No products arising from decomposition of 7 were detected; 4 and 3-amino-1,2,4-triazole were expected as in reactions of $\mathbf{3}$. As was stated above, 3-amino-1,2,4-triazole decomposes to gaseous products and not to 1,2,4-triazole at the highest reaction temperatures.

Another synthesis of 7 was described from the reaction of 3-amino-1,2,4-triazole with sodium dissolved in ethanol and then addition of diethylmalonate ( a $37 \%$ yield of the sodium salt of 7 after recrystalization in water). ${ }^{17}$

Reactions of 2 at $450{ }^{\circ} \mathrm{C}$ with toluene as carrier gas were carried out to detect the presence of radicals. No bibenzyl was found in the products monitored by GC/MS, so a radical chain reaction can be discarded, supporting the mechanism depicted in Scheme 2.

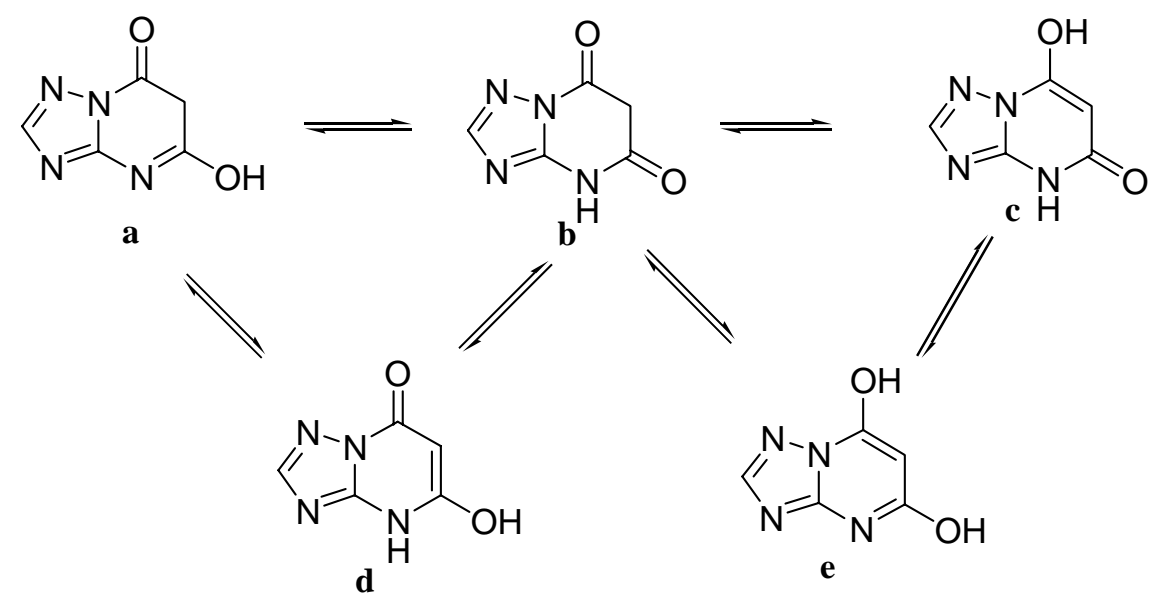

\section{Scheme 3}




\section{Conclusions}

The following conclusions can be derived from the reported results:

1) It is possible to obtain heterocyclic fused pyrimidinones from flash vacuum pyrolysis of azolyl-malonamates. This is an easier methodology in comparison with those previously described by other authors, especially in the case of the thiazole ring. These reactions may be extended to other 2-amino-1,3 azoles to obtain other pyrimidines, which are interesting compounds, since they have wide synthetic possibilities due to the acid carbon as a nucleophile.

2) In reactions of $\mathbf{1}$, reaction temperatures are lowered by the use of solid catalyst without changing reaction products, which is a novel alternative in flash vacuum pyrolysis and the effect of other catalysts should be explored.

\section{Experimental Section}

General Procedures. Flash vacuum pyrolysis reactions were carried out in a vycor glass reactor using a Thermolyne 21100 tube furnace. Oxygen-free dry nitrogen or a mixture of nitrogen/toluene was used as carrier gas. Samples to be pyrolyzed were of $\sim 40 \mathrm{mg}$. Contact times were around $10^{-2} \mathrm{~s}$ and pressures of 0.02 Torr were used. Products were trapped at the liquid air temperature, extracted with solvent and submitted to different analysis or separation techniques. Gas chromatography/mass spectrometry (GC/MS) analysis were performed with a SE - 30 column, using helium as eluent at a flow rate of $1 \mathrm{~mL} / \mathrm{min}$, the heating rate was different for each compound or mixture of compounds. Chemical shifts are reported in ppm downfield from TMS. Column and thin layer chromatography was performed on silica gel. Solvents were analytical grade.

Synthesis of ethyl 3-oxo-3-(1,3-thiazol-2-ylamino)propanoate (1). Compound 1 was prepared by a modification of a previously described methodology, ${ }^{7}$ changing reaction conditions to obtain a better yield. For example, $503 \mathrm{mg}(5.02 \mathrm{mmol})$ of 2-aminothiazole (SIGMA) were dissolved in $3 \mathrm{~mL}$ (19.76 mmol) of ethylmalonate (ICN Biomedicals Inc.) and this mixture was warmed to $100{ }^{\circ} \mathrm{C}$ for $7 \mathrm{~h}$ protected from light and with a distillation apparatus in order to remove the ethanol formed in the reaction. After that time, chloroform was added to dissolve the solid which formed and then n-hexane was added to precipitate the product. The solid was filtered and washed with n-hexane. The product was purified by column chromatography on silica gel 60 and the following solvents: petroleum ether, petroleum ether - benzene, benzene chloroform, chloroform were used. The pure product was obtained in a 72.5\% yield; m.p. 149 $150{ }^{\circ} \mathrm{C}$ (lit. $153^{\circ} \mathrm{C},{ }^{7}$ and $149{ }^{\circ} \mathrm{C}$ ). ${ }^{20}$ 
Synthesis of ethyl 3-oxo-3-(4H-1,2,4-triazol-3-ylamino)propanoate (2). Compound 2 was prepared as follows: $1.002 \mathrm{~g}$ (11.02 mmol) of 3-amino-1,2,4-triazole (SIGMA), $5 \mathrm{~mL}$ (32.81 $\mathrm{mmol}$ ) of diethylmalonate and $5 \mathrm{~mL}$ of DMF were heated in a silicone bath at $140{ }^{\circ} \mathrm{C}$ for $2 \mathrm{~h}$ with a distillation apparatus to eliminate the ethanol formed in the reaction. After that time, a paste was formed and it was dissolved in chloroform and then precipitated with n-hexane. Purification was performed by column chromatography on silicagel 60 and the following solvents: chloroform, chloroform - ethanol, ethanol and $n$-butanol:acetone:water (1:1:1) were used. The yield of pure 2 was $17.1 \%$, m.p. $171-172{ }^{\circ} \mathrm{C}$ (lit. $166-168{ }^{\circ} \mathrm{C}$ ). ${ }^{20}$ It should be mentioned that the other reported synthesis of 2 afforded a 5\% yield by a different procedure. ${ }^{20}$

Flash vacuum pyrolysis of 1 . Reactions were carried out between 250 and $500^{\circ} \mathrm{C}$ and products were identified as follows:

Ethanol: By comparison with authentic sample (Merck). Compounds $\mathbf{3}$ and $\mathbf{5}$ were separated by column chromatography (chloroform:ethanol, 10:1).

5-Hydroxy-7H-[1,3]thiazolo[3,2-a]pyrimidin-7-one (3): ${ }^{1} \mathrm{H}-\mathrm{NMR}$ (200 MHz, DMSO-d $\left.{ }_{6}\right)(\delta$ ppm): 5.30 (s, 1H); 7.38 (d, $J=4.8 \mathrm{~Hz}, 1 \mathrm{H}) ; 7.91$ (d, $J=4.8 \mathrm{~Hz}, 1 \mathrm{H}) .{ }^{8}{ }^{13} \mathrm{C}-\mathrm{NMR}(200 \mathrm{MHz}$, $\mathrm{DMSO}_{6}$ ) $(\delta \mathrm{ppm}): 83.1 ; 111.4 ; 122.0 ; 159.0 ; 168.7 ; 102.2 . \mathrm{MS}: \mathrm{M}^{+}(\mathrm{m} / \mathrm{z}): 168$.

Carbon suboxide (4): MS: $\mathrm{M}^{+}$(m/z): 68 (EPA MS number 504-64-3). ${ }^{21}$ GC/MS were carried out with the reaction crude.

2-Aminothiazole (5): by comparison with authentic sample (SIGMA).

Flash vacuum pyrolysis over solid catalysts. Zeolite. About $250 \mathrm{mg}$ of zeolite HY-22 were included into the reactor mixed with glass wool and about $40 \mathrm{mg}$ of $\mathbf{1}$ were pyrolyzed. The catalyst was preactivated in air at $500-550{ }^{\circ} \mathrm{C}$ for $4 \mathrm{~h}$ (including heating $100{ }^{\circ} \mathrm{C} / \mathrm{h}$ ) before each reaction. The catalyst was pressed, fractured, sieved to the desired particle size fraction of 12 20 mesh and stored under ambient atmosphere. Hydrotalcite: In a typical run, 1,200 g of the catalyst was mixed with glass wool and introduced inside the reactor and about $50 \mathrm{mg}$ of $\mathbf{1}$ were pyrolyzed over hydrotalcite (Mg:Al 2:1) with $\mathrm{CO}_{3}{ }^{\circ}$ as interlaminar anion at $250{ }^{\circ} \mathrm{C}$. The material was calcined at $300{ }^{\circ} \mathrm{C}$ under a nitrogen flow for $3 \mathrm{~h}$ when it was prepared. The catalyst was pressed, fractured, sieved to the desired particle size fraction of $12-20$ mesh and stored under ambient atmosphere.

Flash vacuum pyrolysis of 2. Reactions of 2 were carried out between 300 and $450{ }^{\circ} \mathrm{C}$. The crude reaction mixture was submitted to column chromatography (n-butanol:acetone:water, 1:1:1) to separate 2 . Compounds 6 and $\mathbf{7}$ could not be separated and were analyzed as a mixture with the following spectral data:

Ethyl-3-(3-amino-1H-1,2,4-triazol-1-yl)-3-oxopropanoate (6): ${ }^{1} \mathrm{H}-\mathrm{NMR}$ (200 MHz, DMSO- $d_{6}$ ) ( $\delta \mathrm{ppm}): 1.20$ (t, $J=7.1 \mathrm{~Hz}, 3 \mathrm{H}) ; 2.93-4.17$ (broad, $\left.\mathrm{NH}_{2}\right) ; 3.52$ (s, 2H); 4.12 (q, $J=7.1 \mathrm{~Hz}$, 2H); 8.22 (s, 1H). ${ }^{13} \mathrm{C}-\mathrm{NMR}$ (200 MHz, DMSO-d $)$ ( $\left.\delta \mathrm{ppm}\right): 14.0 ; 42.4 ; 60.8 ; 144.8 ; 155.5$; 164.9; 167.1. MS (m/z): 198 (1.00\% M+); 153 (22.30\%); 152 (8.60\%); 126 (1.82\%); 111 (17.26 \%); 84 (100.00\%); 69 (18.50\%); 57 (15.40\%); 44 (21.9\%); 43 (24.20\%).

5-hydroxy[1,2,4]triazolo[1,5-a]pyrimidin-7(4H)-one (7): ${ }^{1} \mathrm{H}-\mathrm{NMR}$ (200 MHz, DMSO-d $\left.d_{6}\right)(\delta$ ppm): 4.92 (s, broad, $0.8 \mathrm{H}) ; 7.77$ (s, 1H); 11.34 (broad, 1H). ${ }^{13} \mathrm{C}-\mathrm{NMR}$ (200 MHz, DMSO-d $\left.{ }_{6}\right)(\delta$ 
ppm): 79.6; 78.9; $78.3\left(\mathrm{CH}\right.$, structures $\mathbf{c}, \mathbf{d}$ and $\mathbf{e}$ in Scheme 3); 52.3; $52.0\left(\mathrm{CH}_{2}\right.$ structures a and b in Scheme 3); 147.5; 149.6; 157.2 (broad); 164.4 (broad). ${ }^{17}$

Reactions at higher temperatures afforded gaseous products that were distilled to a cold trap and then dissolved in the appropriate solvent for spectroscopic and GC/MS analysis in different experiments. Compounds $\mathbf{8}$ and $\mathbf{9}$ afforded the following spectral data:

1,2,4-Triazole (8): Compared with literature references. ${ }^{22}$

Ethoxyoxazirene (9): ${ }^{1} \mathrm{H}-\mathrm{NMR}\left(200 \mathrm{MHz}, \mathrm{CDCl}_{3}\right)(\delta \mathrm{ppm}): 1.28$ (t, $\left.J=9.1 \mathrm{~Hz}, 3 \mathrm{H}\right) ; 4.21$ (q, $J=$ 9.0 Hz, 2H). MS (m/z): 87 (14.3 \%, M ); 72 (4.54 \%); 58 (0.6 \%); 45 (22.4 \%); 44 (100\%); 43 (54.4\%); 42 (33.3\%). Decomposes at room temperature.

\section{Acknowledgments}

Ioulia T. Gafarova is a fellow from Ministerio de Cultura y Educación (Argentina) through a programme for Russian students and Walter J. Peláez is a fellow from Fundación Antorchas (Argentina). The authors would like to thank Dr. Elena Basaldella (CINDECA - Argentina) for preparation of the zeolite, to Dra. Elizabeth L. Moyano (INFIQC - Argentina) and Dra. Margarita del Arco (University of Salamanca - Spain) for preparation of the hydrotalcite used in this work. This project was funded by TWAS, CONICET (Argentina) and SECyT - UNC (Argentina).

\section{References}

1. Moyano, E. L.; Yranzo, G. I.; Elguero, J. J. Org. Chem. 1998, 63, 8188, and references cited therein.

2. Brown, R. F. G., In Pyrolytic Methods in Organic Chemistry, Academic Press, (London) Ltd. Ed. H. H. Wasserman, 1980, p214.

3. Tseng, P. W.; Chou, C. H. J. Chin. Chem. Soc. 1994, 41, 579.

4. Al-Awadi, N.; Kaul, K.; El-Dusouqui, O. M. E. Can. J. Chem. 1998, 76, 1922.

5. See for example: Brown, R. F. G., In Pyrolytic Methods in Organic Chemistry, Academic Press: London Ltd. H. H. Wasserman, Ed., 1980; p 89.

6. Clarke, D.; Mares, R. W.; McNab, H.; Riddell, F. G. Mag. Res. in Chem. 1994, 32, 255.

7. Saint-Ruf, G.; Silou, Th. J. Heterocycl. Chem. 1979, 16, 1021.

8. Dashkevich, L. B.; Tarasov, B. P.; Modzhibaev, Yu.; Samoretov, M. M. Z. Org. Kimii 1975, 11, , 2200.

9. Canestrari, S.; Sgarabotto, P.; Andreani, A.; Greci, L. J. Chem. Res. (S) 1999, 412.

10. Kandeel, M. M. J. Chin. Chem. Soc. 2001, 48, 37.

11. Ziegler, E.; Bieman, H. Mh. Chem. Bd. 1962, 93, H1, 34.

12. Moyano, E. L.; Yranzo, G. I. J. Org. Chem. 2001, 66, 2943. 
13. Moyano, E. L.; del Arco, M.; Rives, V.; Yranzo, G. I. J. Org. Chem. 2002, 67, 8147.

14. Graubaum, H. J. Prakt. Chem. 1993, 335, 585.

15. Katritzky, A. R.; Feng, D.; Lang, H. J. Org. Chem. 1997, 62, 706.

16. Katritzky, A. R.; El-Zemity, S.; Lang, H. Synth. Comm. 1996, 26, (2), 357.

17. Orihuela, S.; Sánchez, P.; Quirós, M.; Molina, J.; Faure, R. J. Mol. Struct. 1997, 415, 285.

18. Kleinpeter, E.; Koch, A.; Fischer, G.; Askolin, C. P. J. Mol. Struct. 1997, 435, 65.

19. Makisumi, K. Chem. Pharm. Bull. 1961, 801.

20. Katagi, T.; Aoki, M.; Kashiwagi, M.; Ohata, K.; Kohno, S.; Murata, T.; Inoi, T. Chem. Pharma. Bull. 1985, 33, 4878.

21. http://webbook.nist.gov.

22. Pretsch, E.; Clerc, T.; Seibl, J.; Simon, W. Tablas para la Elucidación Estructural de Compuestos Orgánicos por Métodos Espectroscópicos, Ed. Alambra, 1989, H275. 